Background There is a paucity of literature investigating the association between maternal mental health and child injury risk, with many potential confounders difficult to measure and adjust for (e.g. supervision, safety practices). Using a self-controlled case series (SCCS), a within person design where individuals act as their own control, we aimed to investigate the temporal association between child poisoning rates and episodes of maternal depression and anxiety.

Methods Using a cohort of 209,418 mother-child pairs from England who had linked primary care and hospitalisation data from the Clinical Practice Research Datalink and Hospital Episode Statistics, we conducted a SCCS analysis of 2,646 children aged 0-4 who had one or more recorded poisoning between 1997 and 2014. Conditional Poisson regression was used to estimate incidence rate ratios (IRR) for child poisonings during medicated and unmedicated maternal depression and anxiety periods.

Results Child poisoning incidence was higher but IRRs were not significant in the 60 days before depression and/or anxiety episodes compared with well periods. There was no significant increase in poisoning risk during episodes of maternal depression (IRR 1.11, 95\% confidence interval 0.73-1.69), depression with anxiety $(1.19,0.71-1.97)$, or anxiety $(1.19,0.61-2.31)$ when the mother was not prescribed medications for these conditions. Poisoning risk was however significantly elevated during periods of maternal depression treated with medication, with a $43 \%$ higher poisoning rate compared to well periods (1.43, 1.14-1.81).

Conclusions For children who experienced a poisoning, poisoning risk was increased during periods when the mother was treated with medications for depression compared to periods when the mother was well. This finding may reflect that periods of depression treated with medication may be more severe, but does support the need for preventative interventions to ensure safe medication storage and use.

\section{ATLAS AND DASHBOARD OF CHILD AND YOUTH INJURY PREVENTION}

1,2 1 an Pike, ${ }^{3}$ Samar Al-Hajj, ${ }^{2}$ Shannon Piedt, ${ }^{4}$ Alison Macpherson, the CIHR Team in Child and Youth Injury Prevention. 'Department of Paediatrics, University of British Columbia, Canada; ${ }^{2} B C$ Injury Research and Prevention Unit, Child and Family Research Institute, Canada; ${ }^{3}$ American University of Beirut Medical Centre, Lebanon; ${ }^{4}$ York University, Canada

\subsection{6/injuryprev-2016-042156.241}

Background Visual Analytics (VA) is defined as 'the science of analytical reasoning facilitated by interactive visual interfaces'. An interactive VA system helps users make sense of complex and massive data and supports decision-making. The goal of this project was to develop an interactive web-based child and youth injury Atlas and Dashboard and populate it with existing and novel research data from the CIHR Team in Child and Youth Injury Prevention. The aim was to assist injury professionals, practitioners and policy makers to make informed and timely decisions and take action to improve child and youth injury prevention in Canada.

Methods/description of the problem Broad input from the injury prevention community in Canada was sought to finalise the operational requirements for the Atlas and Dashboard. This took place at several time points: 1) the early stages of development to inform the initial mock-up of the site, 2) once the data visualisations were created to determine if they were useful to users, 3) near completion of the site to obtain feedback on usability from the target audience. Visual Interaction Methodology, which helps users derive insights, acquire knowledge and optimise site use, was used to help stakeholders explore and analyse complex data. Results Provincial level child and youth injury mortality, hospitalisation, drowning and transport data were made available to users in two different formats: 1) interactive data visualisations of injury trends and patterns, 2) user defined outputs from selectable menus allowing users to sort, view and query injury data. Injury professionals, practitioners and policy makers informed the look, feel and function of the site and provided feedback that improved the user experience.

Conclusions The Atlas and Dashboard integrates an interactive VA system into a website for child and youth injury prevention aimed at injury professionals, practitioners and policy makers in Canada.

\section{YEARS INJURY SURVEILLANCE IN HARSTAD, NORWAY: A BURN PREVENTION PROGRAM FOR CHILDREN 0-4 YEARS}

'Børge Ytterstad, ${ }^{2}$ Solveig Rostøl Bakken. 'University of Tromsø, Norway; ${ }^{2}$ Harstad Municipality

\subsection{6/injuryprev-2016-042156.242}

Background May 1985, injury surveillance was initiated at Harstad Hospital. Coding was done by the Nordic system for upstream variables. Data from 1985-86 (baseline) showed high thermal burn risk in children 0-4 years old. The consumption of hospital resources for treatment was also high, particularly for scalds in terms of grafting, hygienic precautions, treatment infections and support for patients and parents.

Methods Quasi-experimental design. Harstad (main intervention), six surrounding communities (intervention diffusion) and Trondheim (reference). Based on data on where, when and how injuries occurred, prevention was targeted with a mix of passive and active strategies. Participants interventions: e.g. public health nurses, plumbers, electric appliances stores, politicians, media and the hospital. Scalds caused the most serious burns and were prevented by lowering tap water temperature, installing cooker safeguards and informing parents through home visits and regular health checks for 0-4 children (four yearly).

Results After 10 years burn rates decreased from baseline by $51.5 \%(\mathrm{p}<0.05)$ in Harstad and 40\% in the six municipalities (n.s.) Rates in Trondheim increased by $18.1 \%$ (n.s.). Long term results: The rate scalds/contact burns decreased gradually during 30 years. The serious scalds from receptacles with boiling foodstuff pulled down from the stove were mostly eliminated. Mean yearly hospital bed consumption for burns in children $0-4$ years from Harstad and the six communities was 26.8 during 1985-94 and 2.1 during 1995-2014. During the last two decades, asylum seekers were overrepresented.

Conclusions Programs targeting burns in children can be effective and sustainable. Local injury data provided stimulus for community action. 


\section{Traffic safety: Road infrastructure}

\section{Parallel Tue 1.3}

\section{THE EFFECT OF REDUCED STREET-LIGHTING ON ROAD COLLISIONS IN ENGLAND AND WALES 2000-2013}

Rebecca Steinbach, Chloe Perkins, Ben Armstrong, Phil Edwards. London School of Hygiene and Tropical Medicine

\subsection{6/injuryprev-2016-042156.243}

Background Many local authorities in England and Wales have reduced street lighting at night to save money and reduce carbon emissions. Reductions in street-lighting, however, have attracted considerable public concern about road safety. While there is evidence that increasing street-lighting can reduce collisions it is unknown wheather reducing street-lighting can increase collisions. We quantified the effect of four street lighting adaptation strategies (switch off, part-night lighting, dimming and white light) on road traffic collisions in England and Wales.

Methods Observational study based on analysis of geographically coded police data on road traffic collisions in 62 local authorities. Conditional Poisson models were used to analyse longitudinal changes in the counts of night-time collisions relative to day-time collisions occurring on affected roads during 2000-2013. Effect estimates were adjusted for regional temporal trends in collisions. Results There was no evidence that switch-off (rate ratio 0.97; 95\% confidence interval 0.82 to 1.15 ); part-night lighting (RR 0.95; 95\% CI: 0.84 to 1.07 ); dimming (RR 1.00; 95\% CI: 0.91 to 1.10); or changes to white light (RR 1.01 ; $95 \% \mathrm{CI}: 0.93$ to 1.09) were associated with a change in collisions at night relative to collisions during the day.

Conclusions This study found little evidence of harmful effects of switch off, part-night lighting, dimming, or changes to white light/LEDs on road collisions in England and Wales.

\section{HELMETHON: SUCCESS OF HELMET CAMPAIGN IN AIDING THE HELMET LAW ENFORCEMENT IN A DISTRICT OF SOUTH INDIA}

$\frac{1 \text { Pallavi Sarji Uthkarsh, }{ }^{1} \text { Ashok Jayaram, }{ }^{2} \mathrm{G} \text { Gururaj, }{ }^{1} \mathrm{MS} \text { Rajanna, }{ }^{3} \text { Uthkarsha Lokesh. }}{{ }^{1} \text { Sree Siddhartha Medical College, Tumkur, India; }{ }^{2} \text { Department of Epidemiology and WHO }}$
Collaborating Centre for Injury Prevention, NIMHANS, India; ${ }^{3}$ Department of Maxillofascial Collaborating Centre for Injury Prevention, N
Surjery, Shyamala Reddy Dental College, India

10.1136/injuryprev-2016-042156.244

Background Road traffic injuries were the leading cause of injury with a mortality rate of $18.1 / 1,00,000 /$ year and accounted for $38 \%$ of fatal injury deaths and $39 \%$ of nonfatal injuries during Jan 2011-Dec 2011 in Tumkur. Nearly 26\% of fatal and 38\% of non-fatal road traffic injuries were sustained in the age group of 15-29 years. Two wheeler riders accounted for $45 \%$ of fatal and $35.5 \%$ of nonfatal injuries. Head injury is the most common cause of death among two wheeler users. Helmet is the only vaccine to prevent head injuries. Though there was a law about compulsory wearing of helmet in the state, it was never enforced in the district and helmet usage rate in a district before campaign was varied from $1 \%$ to $5 \%$.

Methods 'Helmethon', was a campaign initiated and led by a Medical college with the support of other universities. Campaign targeted the public with special focus 1 . To create awareness among public about helmet safety, with special focus on youth. 2 . To promote helmet usage 3. To draw stakeholder's attention towards importance of helmet safety and need for enforcement. This campaign was designed with the inputs from youth, so that more youth would be part of this.

Multi faceted Campaign was carried out for a period of three months. It had various components like, Helmet education,HELfie challenge in a social media, bike rally with a flash mob and wear helmet pledge at different campus and public places, an intercollegiate literary and cultural event with the theme 'HeLMeT' and a first ever marathon-HELMETHON, in a district for Helmet.

Results Campaign was successful in bringing the stakeholders together with good community participation and Helmet law was enforced in Tumkur district in less than a fortnight following the campaign. Now helmet usage rate among riders has increased to $80 \%$.

Conclusions A well planned and committed helmet campaign shall influence stakeholders to enforce the helmet law and sensitises the community regarding helmet safety and encourages them to use it.

\section{IMPLEMENTATION AND EVALUATION OF A PROGRAM TO INCREASE BOOSTER SEAT USE AMONG SCHOOL- AGE CHILDREN}

Merissa A Yellman, Maria Isabel Colunga, Mary A McCoy, Shelli Stephens-Stidham, Gregory $\mathrm{R}$ Istre. Injury Prevention Centre of Greater Dallas, USA

\subsection{6/injuryprev-2016-042156.245}

Background Between the 2011-2012 and 2014-2015 school years, the Injury Prevention Centre of Greater Dallas (IPC) implemented Give Kids a Boost (GKB), a one-year, multi-faceted, school-based booster seat program in a total of 8 target schools in the Dallas area. Through the program, the IPC trained school staff and parents to be booster seat champions. Together, they conducted parent presentations, provided fact sheets and tailored communication, educated parents at dismissal, and offered inspection stations. This study aimed to evaluate the effectiveness of all of the IPC's $G K B$ projects in increasing booster seat use among children 4-7 years of age in motor vehicles.

Methods The IPC conducted observation surveys at target and comparison schools before project implementation (pre-intervention, $\mathrm{P}_{0}$ ), 1-4 weeks after project implementation (early postintervention, $\mathrm{P}_{1}$ ), and 4-5 months after project implementation (late post-intervention, $\mathrm{P}_{2}$ ). Observations were conducted at morning drop-off times near school entrances. A standardised form was used to document the child's restraint use, age/race/gender, seating position, vehicle type, and driver belt use. $\mathrm{P}_{0}, \mathrm{P}_{1}$, and $\mathrm{P}_{2}$ time periods were analysed to compare the changes in booster seat use across each project. Observations were conducted in the same manner at the comparison schools, which received no intervention.

Results In the 8 target schools, booster seat use for children 4-7 years of age increased an average of 20.9 percentage points between $\mathrm{P}_{0}$ and $\mathrm{P}_{1}\left(\mathrm{P}_{0}=4.8 \%, \mathrm{P}_{1}=25.7 \%\right.$; O.R. $=6.9,95 \%$ CI: 5.5 to $8.7 ; \mathrm{P}<0.001)$. Comparison schools $(\mathrm{n}=14)$ experienced no change in booster seat use $\left(\mathrm{P}_{0}=4.7 \%, \mathrm{P}_{1}=4.9 \%\right.$; $\mathrm{O}$. $\mathrm{R} .=1.0,95 \% \mathrm{CI}: 0.8$ to $1.3 ; \mathrm{P}=0.4)$. In 3 of the 4 years, booster seat use remained at a high level at the $\mathrm{P}_{2}$ time period $\left(\mathrm{P}_{2}=31.5 \%\right)$. 